\title{
AVALIAÇ̃̃o PATOLÓGICA NA CENTRAL DE AULAS IV DA UFERSA CAMPUS MOSSORÓ DE ACORDO COM A METODOLOGIA DA MATRIZ GUT
}

\author{
SILVA, ADJA RAYFANE MEDEIROS \\ Pós-graduanda \\ IPOG \\ CE; Brasil \\ rhayfanem@gmail.com \\ SILVEIRA, ARTHURO MUNAY DANTAS DA \\ Mestrando \\ UFRN \\ RN; Brasil \\ arthuromds@hotmail.com
}

\author{
GUILHERME, ANA TÁLIA PINTO \\ Professora \\ Universidade de Fortaleza - Unifor \\ CE; Brasil \\ anatalia@unifor.br
}

\author{
OLIVEIRA, FELIPE AUGUSTO DANTAS DE \\ Professor \\ UFERSA \\ RN; Brasil \\ felipe.dantas@ufersa.edu.br
}

\section{RESUMO}

É necessário um correto diagnóstico da anomalia para se determinar as providências que devem ser tomadas diante de uma obra que apresente alguma manifestação patológica, sendo possível agir de forma eficiente, recuperando-a e aumentando sua vida útil. Este trabalho traz um estudo detalhado das manifestações patológicas na Central de aulas IV, a qual a partir das causas dessas anomalias, pôde-se propor alternativas de intervenção de acordo com a Metodologia da matriz GUT, que define as prioridades a partir dos valores dos fatores de riscos (Fator de Risco $=$ GxUxT), quanto maior o fator, mais prioritária será a busca para a solução do problema. A maioria das manifestações patológicas identificadas na central de aulas IV estão relacionadas a umidade e recalque diferencial, repetindo-se por todo o prédio. O fato da edificação não possuir impermeabilização na laje e ter muitas telhas quebradas, caimento inadequado, resulta em vários problemas patológicos decorrente de umidade. Foi visto que as raízes e a água que é lançada proveniente dos aparelhos de ar-condicionado na fundação podem ter causado o adensamento do solo, assim causando o aparecimento das fissuras, desaprumos, piso afundado. As raízes de árvores próximas as fundações também podem ter contribuído para o recalque diferencial do prédio. O Método GUT serviu para o estabelecimento da ordem de prioridade de resolução entre os problemas encontrados, sendo possível realizar a hierarquização dos riscos. Fica como recomedação um programa de manutenção emergencial e outro de manutenção preventiva, podendo ser embasada na metodologia aplicada neste trabalho.

Palavras-chave: Patologia das construções, Obras públicas, Manifestações patológicas, Diagnóstico, Manutenção.

\section{ABSTRACT}

A correct diagnosis of the anomaly is necessary to determine the steps that should be taken in front of a construction that presents some pathological manifestation, being able to act efficiently, recovering it and increasing its useful life. This paper presents a detailed study of the pathological manifestations in the Central Classroom IV, which from the causes of these anomalies, could be proposed alternative intervention according to the GUT matrix methodology, which defines the priorities from the values of the risk factors. (Risk Factor $=$ GxUxT), the higher the factor, the more priority will be the search to solve the problem. Most of the pathological manifestations identified in the Central Classroom IV center are related to humidity and differential repression, repeating throughout the building. The fact that the building does not have waterproofing on the slab and has many broken roof tiles, improper fit, results in several pathological problems due to moisture. It has been seen that the roots and water that is released from the air conditioners in the foundation may have caused the soil consolidation, thus causing the appearance of cracks, unevenness, sunken floors. Tree roots near foundations may also have contributed to the building's differential repression. The GUT Method served to establish the order of resolution priority among the problems encountered, and it was possible to perform the risk hierarchy. It is recommended as an emergency maintenance program and another preventive maintenance program, and can be based on the methodology applied in this work.

Keywords: Pathology of buildings, Public works, Pathological manifestations, Diagnosis, Maintenance. 


\section{INTRODUÇÃO}

De acordo com Helene (2001), patologia é a parte da Engenharia Moderna que examina os sintomas, o mecanismo, as origens e as causas das falhas nas edificações. A origem das manifestações patológicas em uma estrutura são decorrentes de um conjunto de fatores, que desencadeiam diversas anomalias nas edificações. Conhecer a origem destas manifestações é de extrema importância, visto que um correto diagnóstico da anomalia é necessário para se determinar quais providências devem ser tomadas diante de um prédio que apresenta alguma manifestação patológica, sendo possível agir de forma eficiente, recuperando-o (TUTIKIAN e PACHECHO, 2013; NAZARIO e ZANCAN, 2011).

De acordo com Oliveira (2016) são verificados altos índices de manifestações patológicas nos prédios públicos, que vão desde sobrecargas imprevistas nas estruturas até a ataques de agentes químicos, isto se dá pela falta de programas de planejamento e/ou execução de manutenções preventivas nas construções, que pode desencadear desgaste e, até mesmo, colapso da estrutura, podendo comprometer e prejudicar a segurança dos usuários. Tutikian e Pacheco (2013) complementam que após a etapa de diagnóstico, torna-se necessário selecionar a melhor alternativa de intervenção para o problema, priorizando-as se necessário.

A Engenharia moderna propõe ferramentas que auxiliam estrategicamente na tomada de decisão, dentre elas está a metodologia da matriz GUT, ferramenta que é muito utilizada por administradores, porém sendo facilmente adaptada para a construção civil por se tratar de uma ferramenta prática e muito intuitiva. Segundo Gomes (2006) a matriz GUT é uma forma de tratar problemas, com o objetivo de priorizá-los, levando em consideração a gravidade do problema, que é o impacto que ele causaria a longo prazo sobre pessoas, organizações ou processos, na hipótese do mesmo não ser resolvido. Outro ponto a ser considerado é a urgência, que seria a relação com o tempo necessário ou disponível para resolver o problema, por último a tendência, que é a avaliação da tendência de crescimento, redução ou desaparecimento do problema.

Para Periard (2011) um dos maiores benefícios em empregar a Matriz GUT é que ela consegue quantificar os problemas da empresa, tornando viável a priorização das ações preventivas ou corretivas para a eliminação parcial ou total do problema.

Diante do expposto, este trabalho abordará um estudo das manifestações patológicas presentes na Central de aulas IV da Universidade Federal Rural do Semi-Árido (UFERSA), Campus Mossoró, aplicando a metodologia da matriz GUT (Gravidade, Urgência e Tendência) com o intuito de priorizar a solução desses problemas. De acordo com Ferreira $e t$ al (2018) quanto maior o fator de risco (Fator de Risco = GxUxT), mais prioritária será a solução do problema encontrado.

\section{MATERIAIS E MÉTODO}

A investigação de campo foi realizada na Central de aulas IV da UFERSA, campus Mossoró e nas suas adjacências. O prédio foi concluído em Maio de 2009, possui área de $939 \mathrm{~m}^{2}$, 12 salas de aulas, 5 banheiros, sendo eles femininos e masculinos e 01 copa. O prédio é destinado a aulas dos cursos de Administração, Agronomia e Engenharia Química. A Figura 1 mostra a fachada da Central de aulas IV.

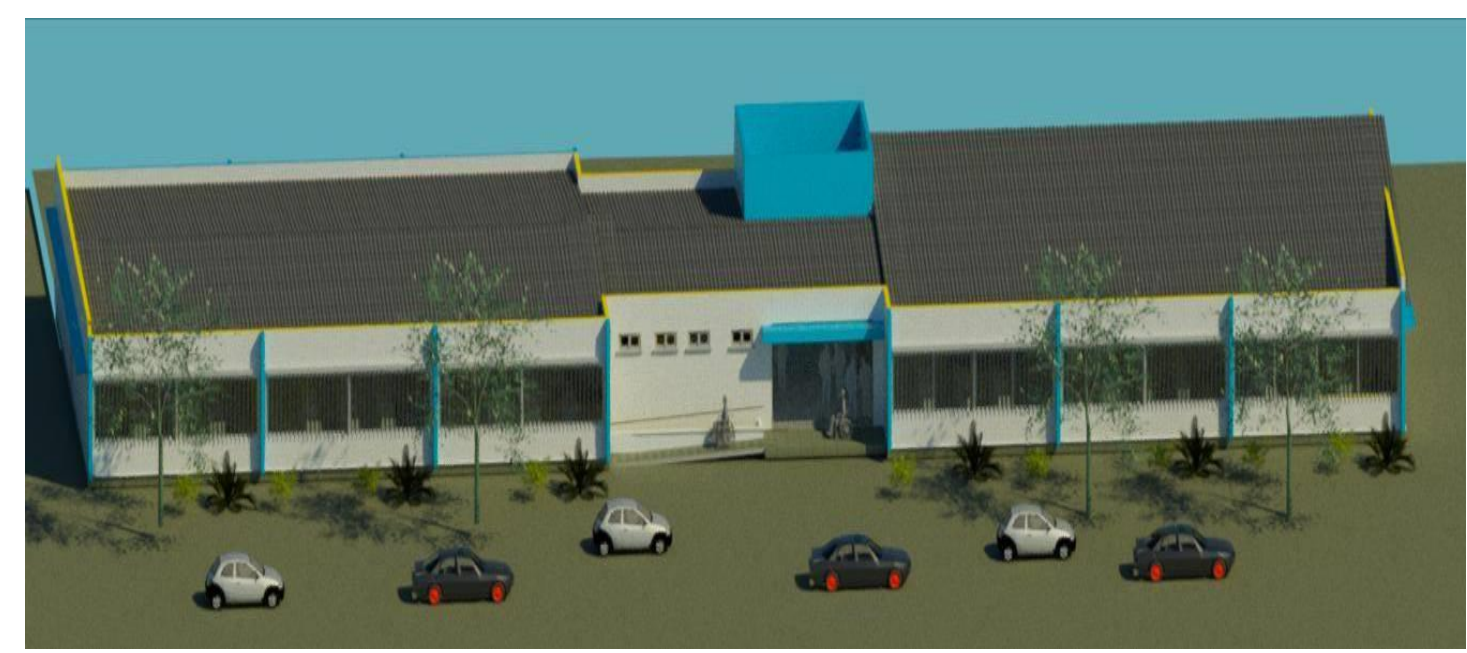

Figura 1 - Modelagem 3D no software REVIT da Central de aulas IV.

Fonte: Autoria Própria (2019). 
O estudo constitui de uma pesquisa de campo de ordem quali-quantitativa, pois foi feita a coleta dos dados e aplicada as ferramentas técnicas necessárias, capazes de identificar os fenômenos (CORREA, 2003). Para identificar os agentes causadores das manifestações patológicas foram realizados ensaios destrutivos e não-destrutivos. Para avaliar as condições do concreto endurecido do pilar foram realizados dois ensaios não-destrutivos, o ensaio de esclerometria e o ensaio de ultrassom no concreto. Os ensaios realizados para a análise do solo utilizado no aterro para a fundação foram os de sondagem SPT, granulometria, limites de liquidez e de plasticidade, compactação e, ISC (índice de suporte califórnia).

\section{RESULTADOS}

\subsection{Inspeção in loco}

As manifestações patológicas são originadas por falhas que incidem durante a realização de uma ou mais das atividades do processo da construção civil, no Quadro 1 pode-se observar as manifestações patológicas detectadas na Central de aulas IV acompanhadas das possíveis causas.

Quadro 1 - Manifestações patológicas detectadas na Central de aulas IV

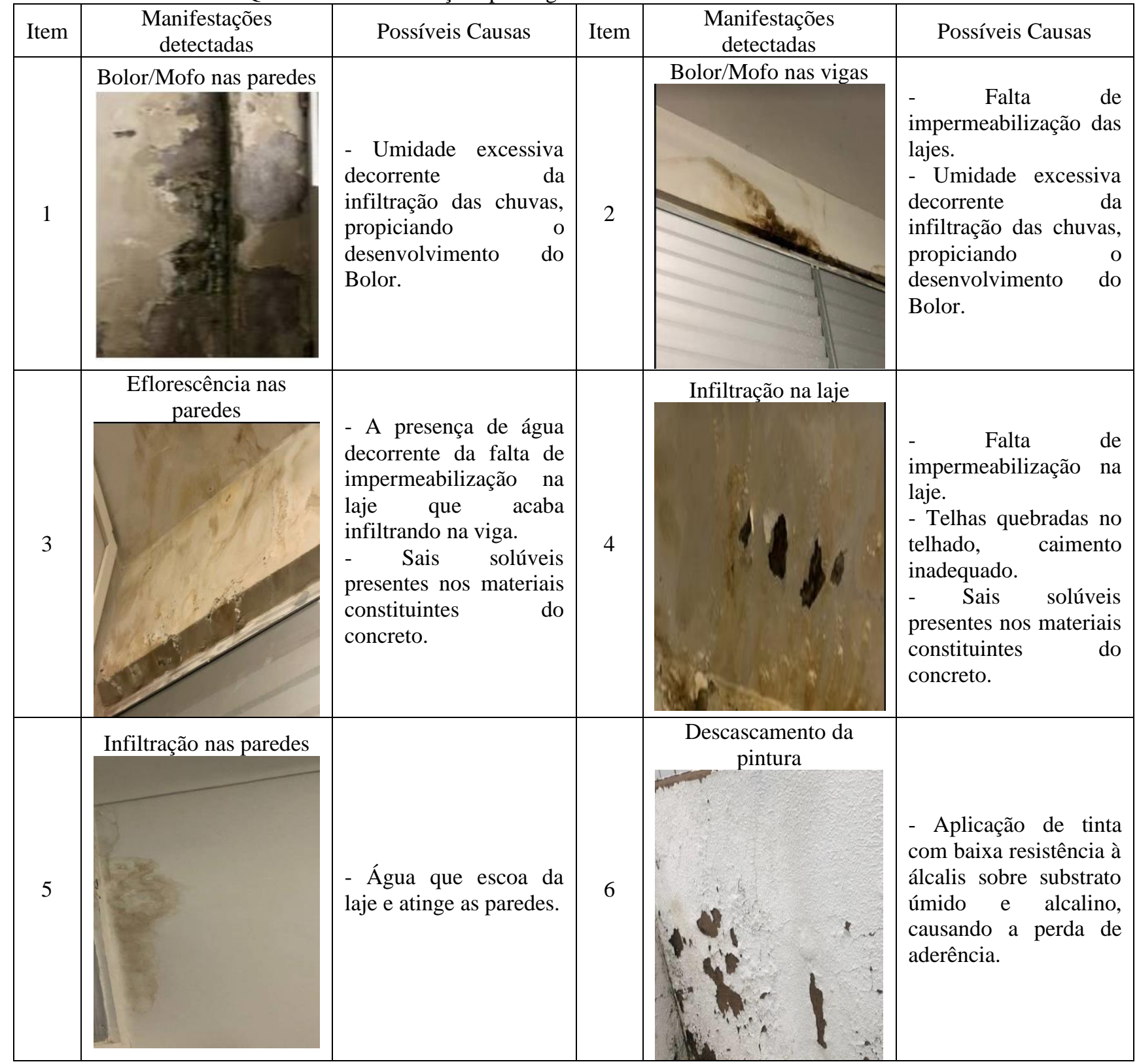

(Continua) 
Quadro 1 - Manifestações patológicas detectadas na Central de aulas IV

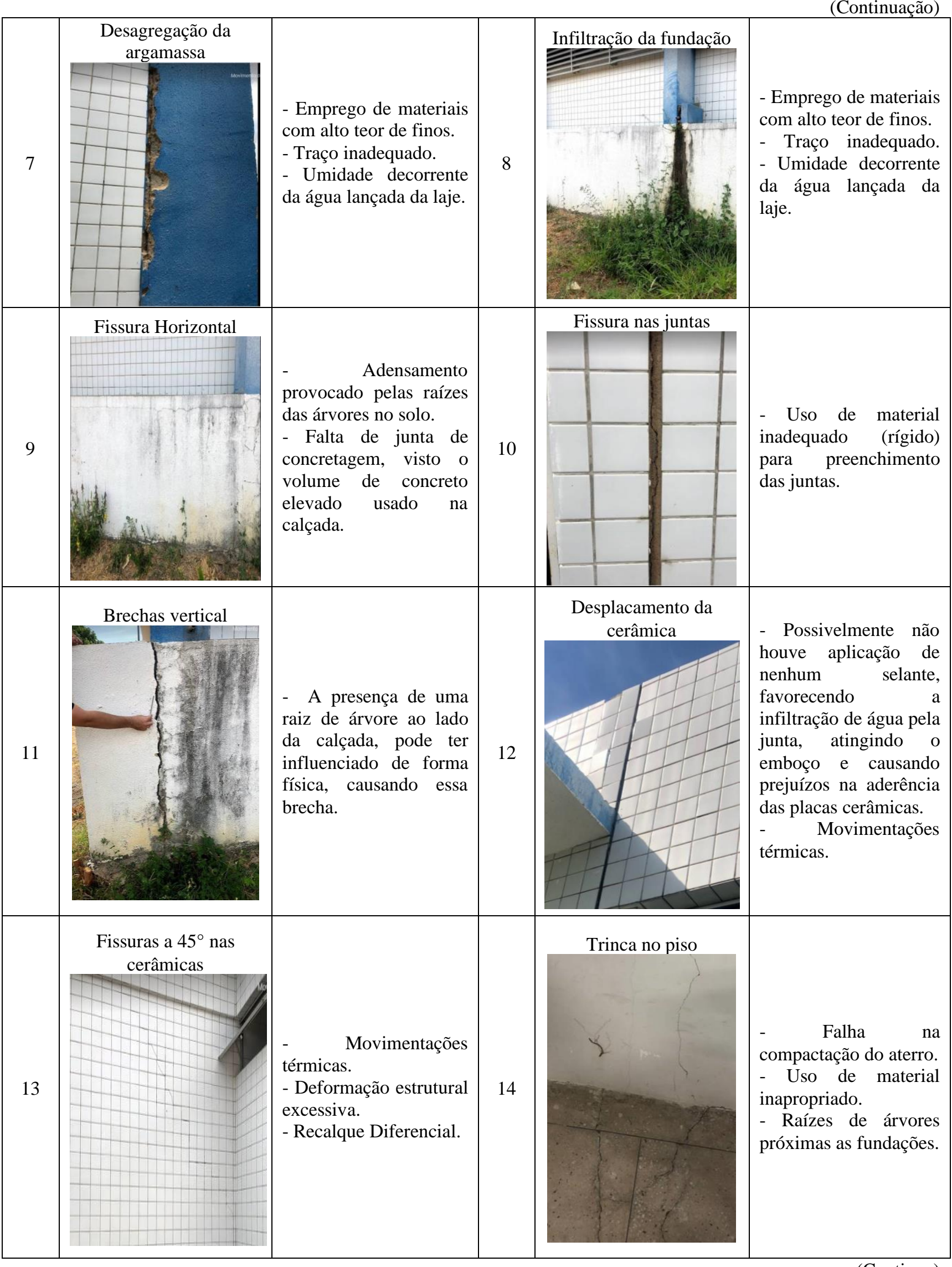

(Continua) 
Quadro 1 - Manifestações patológicas detectadas na Central de aulas IV

\begin{tabular}{|c|c|c|c|c|c|}
\hline 15 & Recalque no piso & $\begin{array}{l}\text { - Falha na compactação } \\
\text { do aterro. } \\
\text { - Uso de material } \\
\text { inapropriado. } \\
\text { - Raízes de árvores } \\
\text { próximas as fundações. } \\
\text { - Recalque diferencial } \\
\text { no prédio. }\end{array}$ & 16 & Recalque na calçada & $\begin{array}{l}\text { Falha na } \\
\text { - compactação do aterro. } \\
\text { - Uso de material } \\
\text { inapropriado. } \\
\text { - Raízes de árvores } \\
\text { próximas as fundações }\end{array}$ \\
\hline 17 & $\begin{array}{c}\text { Fissuras verticais na } \\
\text { viga }\end{array}$ & $\begin{array}{l}\text { - Deficientemente } \\
\text { armadas ao } \\
\text { cisalhamento. } \\
\text { - Insuficiência ou mau } \\
\text { posicionamento dos } \\
\text { estribos. } \\
\text { - Ação de sobrecargas } \\
\text { não previstas. }\end{array}$ & 18 & Fissura a $45^{\circ}$ & $\begin{array}{l}\text { - Dimensionamento } \\
\text { inadequado das } \\
\text { fundações. } \\
\text { - Recalque diferencial } \\
\text { do prédio causado } \\
\text { pelas raízes de árvores } \\
\text { próximas as fundações. }\end{array}$ \\
\hline 19 & Trinca a $45^{\circ}$ & $\begin{array}{l}\text { - Dimensionamento } \\
\text { inadequado das } \\
\text { fundações. } \\
\text { - Recalque diferencial } \\
\text { do prédio causado pelas } \\
\text { raízes de árvores } \\
\text { próximos as fundações. }\end{array}$ & 20 & Rachadura a $45^{\circ}$ & $\begin{array}{l}\text { - Dimensionamento } \\
\text { inadequado das } \\
\text { fundações. } \\
\text { - Recalque diferencial } \\
\text { do prédio causado } \\
\text { pelas raízes de árvores } \\
\text { próximas as fundações. }\end{array}$ \\
\hline 21 & Fendas a $45^{\circ}$ & $\begin{array}{l}\text { - Dimensionamento } \\
\text { inadequado das } \\
\text { fundações. } \\
\text { - Recalque diferencial } \\
\text { do prédio causado pelas } \\
\text { raízes de árvores } \\
\text { próximas as fundações. }\end{array}$ & & & \\
\hline
\end{tabular}

Fonte: Autoria Própria (2019).

A ocorrência das manifestações patológicas pode ser observada na Figura 2. 


\begin{tabular}{|c|c|c|c|c|c|c|c|c|c|c|c|c|c|c|c|c|c|c|c|c|}
\hline \multirow{3}{*}{ Manifestação patológica } & \multicolumn{20}{|c|}{ AMBIENTL } \\
\hline & Sala & a Sala & Sala & Sala & Sala & Sala & Sala & Sala & Sala & Sala & Salas & Sala BWCF & BWC & BWCM & $B W C$ & Parte Ext. & Parte & & Hall de & \\
\hline & 1 & 2 & 3 & 4 & 5 & 6 & 7 & 8 & 9 & 10 & 11 & 12 Acessi. & Fem. & Acessi. & Mas. & Frente & Atrás & Corfecories & Entrada & Calçadas \\
\hline \multicolumn{21}{|l|}{ Infiltração na laje } \\
\hline \multicolumn{21}{|l|}{ Inflitração na viga } \\
\hline \multicolumn{21}{|l|}{ Infittraçào na parede } \\
\hline \multicolumn{21}{|l|}{ Fissuras a $45^{\circ}$ nas ceramicas } \\
\hline \multicolumn{21}{|l|}{ Desplacamento de ceramicas } \\
\hline \multicolumn{21}{|l|}{ Recalque no piso } \\
\hline \multicolumn{21}{|l|}{ Fissuras no piso } \\
\hline \multicolumn{21}{|l|}{ Fissuras à $45^{\circ}$ nas paredes } \\
\hline \multicolumn{21}{|l|}{ Trincas a $45^{\circ}$ nas paredes } \\
\hline \multicolumn{21}{|l|}{ Rachaduras nas paredes } \\
\hline \multicolumn{21}{|l|}{ Fendas } \\
\hline \multicolumn{21}{|l|}{ Brechas } \\
\hline \multicolumn{21}{|l|}{ Desagregaçào da pintura } \\
\hline \multicolumn{21}{|l|}{ Bolor } \\
\hline \multicolumn{21}{|l|}{ Fissuras verticiais em vigas } \\
\hline \multicolumn{21}{|l|}{ Legenda: } \\
\hline Ocorrência & $\mathrm{Cot}$ & & & & & & & & & & & & & & & & & & & \\
\hline Nenhuma vez & & & & & & & & & & & & & & & & & & & & \\
\hline lvez & & & & & & & & & & & & & & & & & & & & \\
\hline 2 vezes & & & & & & & & & & & & & & & & & & & & \\
\hline 3 veres & & & & & & & & & & & & & & & & & & & & \\
\hline 4 vezes & & & & & & & & & & & & & & & & & & & & \\
\hline Mais de 4 vezes & & & & & & & & & & & & & & & & & & & & \\
\hline
\end{tabular}

Figura 2 - Ocorrência das Manifestações Patológicas na Central de Aulas IV Fonte: Autoria Própria (2019). 


\subsection{Ensaios realizados}

O valor médio do índice esclerométrico final foi de $17 \mathrm{MPa}$, um valor razoável, visto que em 2009, ano de entrega do prédio, a norma vigente utilizada para os Projetos de Estruturas de Concreto, ABNT NBR 6118: 2007, exigia um $f c k$ do concreto com no mínimo $15 \mathrm{MPa}$ para a classe de agressividade ao qual o meio está exposto, então sendo maior que o valor mínimo permitido. A inexistência de memorial descritivo impede-nos de conhecer o $f c k$ pretendido no dimensionamento.

Com o ensaio de ultrassom foi possível determinar a velocidade de propagação de onda ultrassônica para relacionar com a qualidade do concreto, de acordo com o estudo de Whitehurst (1966) e Rincon et al (1998) apud Medeiros (2007). Eles compararam a velocidade de propagação da onda com a qualidade do concreto e, classificaram a qualidade o concreto desde ruim a excelente. Comparando esses valores com os obtidos em ensaio, chegamos aos resultados apresentados na Tabela 1. É possível que exista uma fissura no ponto 7, visto que existe a raiz de uma árvore na frente do pilar, que pode estar interferindo de forma física na sua integridade. Nos outros pontos pode-se observar um concreto com qualidade regular a ótima.

Tabela 1 - Velocidade de Propagação das Ondas

\begin{tabular}{ccccc}
\hline Pontos & Tempo $(\mu \mathrm{s})$ & Distância $(\mathrm{m})$ & Velocidade $(\mathrm{m} / \mathrm{s})$ & Classificação \\
\hline 4 & 42,90 & 0,18 & 4195,80 & Ótimo \\
5 & 35,40 & 0,13 & 3672,32 & Ótimo \\
7 & 102,90 & 0,18 & 1749,27 & Ruim \\
8 & 48,90 & 0,13 & 2658,49 & Regular \\
\hline
\end{tabular}

Fonte: Autoria Própria (2019).

A sondagem de reconhecimento simples com SPT foi realizada pela empresa WM Engenharia, que seguiu as diretrizes da ABNT NBR 6484:2001. Foram realizadas 02 sondagens SPT na parte posterior da edificação da Central de aulas IV, representadas na Figura 3.

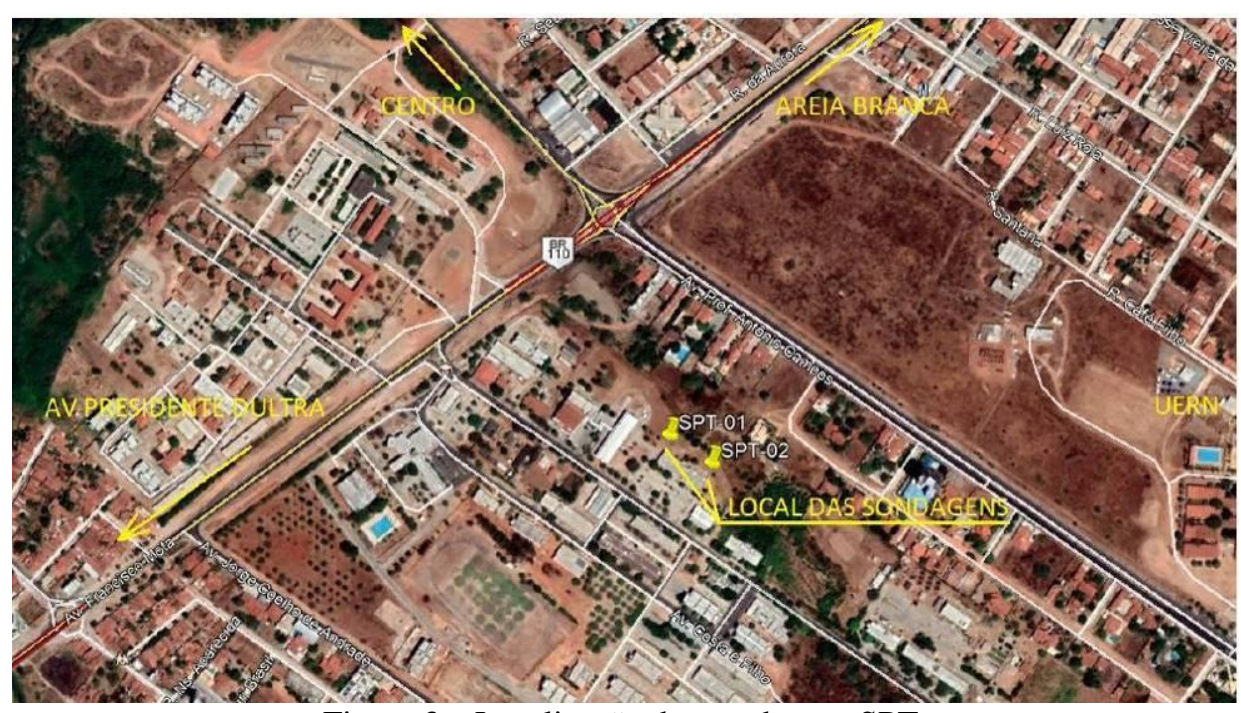

Figura 3 - Localização das sondagens SPT.

Fonte: WM Engenharia (2019).

Conforme estudo e análise de solo, percebeu-se que o solo encontrado nas sondagens apresenta grande resistência a penetração, pois foi utilizado todos os métodos previstos na NBR 6484 (2001) e não houve avanço na perfuração. Na sondagem SPT-01 foi encontrada pouca variação nas amostras coletadas, pois o solo retirado da perfuração foi classificado por ensaio tátil-visual basicamente como argila arenosiltosa friável, que varia entre rija a dura, cor vermelha, com presença de detrito de rocha calcária e pequenos seixos. A sondagem chegou ao seu limite impenetrável, 1,2 metros, até está profundidade a perfuração foi a seco e por circulação de fluidos com revestimento. A sondagem 


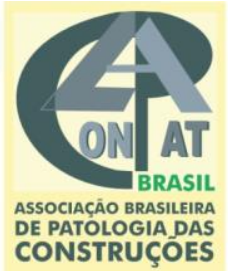

SPT-02, apresentou as mesmas características da anterior, conforme recomendação normativa houve mais duas tentativas de perfuração ao lado de cada sondagem (SPT-01 e SPT-02), porém as características do solo encontrado foram as mesmas das sondagens anteriores.

\subsection{Priorização das manifestações patólogicas na central de aulas IV}

Foram classificadas as manifestações patológicas identificadas e analisadas no estudo, sendo priorizadas de acordo com as variáveis da Metodologia da Matriz GUT representadas na Tabela 2, de acordo com os parâmetros da metodologia adotada.

Tabela 2 - Tabela de Priorização aplicando a Matriz GUT

\begin{tabular}{ccccccc}
\hline $\begin{array}{c}\text { Manifestação } \\
\text { Patológico }\end{array}$ & Diagnóstico & G & U & T & GUT & $\begin{array}{c}\text { Grau de } \\
\text { priorização }\end{array}$ \\
\hline 1 & Bolor/Mofo nas paredes & 1 & 2 & 2 & 4 & $18^{\circ}$ \\
2 & Bolor/Mofo nas vigas & 2 & 2 & 2 & 8 & $16^{\circ}$ \\
3 & Eflorescência nas vigas & 2 & 3 & 4 & 24 & $6^{\circ}$ \\
4 & Eflorescência nas lajes & 2 & 3 & 4 & 24 & $7^{\circ}$ \\
5 & Infiltração nas paredes & 2 & 1 & 2 & 4 & $21^{\circ}$ \\
6 & Descascamento da pintura & 2 & 1 & 2 & 4 & $19^{\circ}$ \\
7 & Desagregação da argamassa & 2 & 3 & 3 & 18 & $9^{\circ}$ \\
8 & Bolor/Mofo nas calçadas & 3 & 4 & 5 & 60 & $4^{\circ}$ \\
9 & Fissura Horizontal & 2 & 1 & 2 & 4 & $20^{\circ}$ \\
10 & Fissuração na junta estrutural & 4 & 1 & 1 & 4 & $17^{\circ}$ \\
11 & Brecha vertical & 2 & 3 & 3 & 18 & $10^{\circ}$ \\
12 & Desplacamento das cerâmicas & 3 & 2 & 3 & 18 & $8^{\circ}$ \\
13 & Fissuras a 45 nas cerâmicas & 2 & 2 & 3 & 12 & $11^{\circ}$ \\
14 & Trincas no piso & 2 & 2 & 3 & 12 & $13^{\circ}$ \\
15 & Recalque do piso & 2 & 2 & 2 & 8 & $14^{\circ}$ \\
16 & Recalque da calçada & 2 & 2 & 2 & 8 & $15^{\circ}$ \\
17 & Fissuras verticais nas vigas & 4 & 4 & 5 & 80 & $2^{\circ}$ \\
18 & Fissuras a 45 nas paredes & 2 & 2 & 3 & 12 & $12^{\circ}$ \\
19 & Trincas a 45 nas paredes & 3 & 3 & 4 & 36 & $5^{\circ}$ \\
20 & Rachaduras a 45 nas paredes & 4 & 4 & 4 & 64 & $3^{\circ}$ \\
21 & Fendas a 45 nas paredes & 4 & 5 & 4 & 80 & $1^{\circ}$ \\
\hline
\end{tabular}

Fonte: Autoria Própria (2019).

Os produtos obtidos através da aplicação do método expressam a análise da problemática de cada manifestação, resultando em uma ordem de priorização, como algumas manifestações tiveram o mesmo número GUT, foi preciso uma tomada de decisão, então a critério dos autores, pode-se observar no Quadro 2, a ordem da priorização seguido da terapêutica indicada. 
Quadro 2 - Resultado da Priorização

\begin{tabular}{|c|c|c|c|c|}
\hline $\begin{array}{l}\text { Problema } \\
\text { Patológico }\end{array}$ & Diagnóstico & GUT & $\begin{array}{c}\text { Grau de } \\
\text { Priorização }\end{array}$ & Terapêutica Indicada \\
\hline $\begin{array}{l}\text { Manifestação } \\
21\end{array}$ & $\begin{array}{l}\text { Fendas a } 45^{\circ} \\
\text { nas paredes }\end{array}$ & 80 & $1^{\circ}$ & $\begin{array}{l}\text { 1. Causa: Recalque diferencial, solução: fazer o reforço de fundação com } \\
\text { estacas mega de concreto, que na prática é a solução utilizada em mais } \\
\text { de } 90 \% \text { dos casos de reforço de fundação, pela sua praticidade, } \\
\text { disponibilidade e excelente relação custo-benefício. } \\
\text { 2. Deve-se remover a argamassa da parede até chegar no tijolo em uma } \\
\text { faixa de } 25 \mathrm{~cm} \text { de cada lado da fenda ( } 50 \mathrm{~cm} \text { no total). Fazer um sulco } \\
\text { na região da abertura de pelo menos } 0,5 \mathrm{~cm} \text { de profundidade. } \\
\text { Preencher com selante elástico de baixo módulo de elasticidade. } \\
\text { Deixar secar. Molhar a região e fixar uma tela eletro soldada (fio de } 1 \\
\text { mm) ou tela plana na região de forma centralizada (a fixação pode ser } \\
\text { feita com pinos ou chapisco). Aplicar argamassa polimérica } \\
\text { semirrígida. Esperar curar. Aplicar, sobre a massa, manta poliéster. } \\
\text { Fazer o acabamento com massa acrílica e tinta acrílica (nunca utilizar } \\
\text { PVA em reparo de aberturas). }\end{array}$ \\
\hline $\begin{array}{l}\text { Manifestação } \\
17\end{array}$ & $\begin{array}{c}\text { Fissuras } \\
\text { verticais nas } \\
\text { vigas }\end{array}$ & 80 & $2^{\circ}$ & $\begin{array}{l}\text { 1. Recomenda-se que se faça o projeto estrutural para verificar como a } \\
\text { estrutura está sendo solicitada. } \\
\text { 2. A vigas devem ser reforçadas ao esforço cortante, a indicação é o } \\
\text { reforço com fibra de carbono, mas podem ser reforçadas por outros } \\
\text { meios. } \\
\text { 3. O reforço das estruturas de concreto armado com fibra de carbono } \\
\text { serve para absorver as tensões tangenciais (de cisalhamento) } \\
\text { decorrente dos esforços cortantes. }\end{array}$ \\
\hline $\begin{array}{l}\text { Manifestação } \\
20\end{array}$ & $\begin{array}{c}\text { Rachaduras a } \\
45^{\circ} \text { nas } \\
\text { paredes }\end{array}$ & 64 & $3^{\circ}$ & $\begin{array}{l}\text { 1. Deve-se remover a argamassa da parede até chegar no tijolo em uma } \\
\text { faixa de } 25 \mathrm{~cm} \text { de cada lado da rachadura }(50 \mathrm{~cm} \text { no total). Fazer um } \\
\text { sulco na região da abertura de pelo menos } 0,5 \mathrm{~cm} \text { de profundidade. } \\
\text { Preencher com selante elástico de baixo módulo. Deixar secar. Molhar } \\
\text { a região e fixar uma tela eletro soldada (fio de } 1 \mathrm{~mm} \text { ) ou tela plana na } \\
\text { região de forma centralizada (a fixação pode ser feita com pinos ou } \\
\text { chapisco); } \\
\text { 2. Aplicar argamassa polimérica semirrígida. Esperar curar. Aplicar, } \\
\text { sobre a massa, manta poliéster. Fazer o acabamento com massa } \\
\text { acrílica e tinta acrílica (nunca utilizar PVA em reparo de aberturas). }\end{array}$ \\
\hline $\begin{array}{l}\text { Manifestação } \\
8\end{array}$ & $\begin{array}{c}\text { Infiltração no } \\
\text { solo de } \\
\text { fundação } \\
\end{array}$ & 60 & $4^{\circ}$ & $\begin{array}{l}\text { 1. Remanejamento da água proveniente dos aparelhos de ar- } \\
\text { condicionado e lavagem de pisos, para não infiltrarem no solo. }\end{array}$ \\
\hline $\begin{array}{l}\text { Manifestação } \\
19\end{array}$ & $\begin{array}{l}\text { Trincas a } 45^{\circ} \\
\text { nas paredes }\end{array}$ & 36 & $5^{\circ}$ & $\begin{array}{l}\text { 1. Escarear a parede na largura da tela selante, aprofundando cerca de } 2 \\
\text { mm; } \\
\text { 2. Fazer um sulco na região da trinca, limpar a região com pano úmido e } \\
\text { esperar secar; } \\
\text { 3. Aplicar o mástique no sulco da trinca e deixar secar. Aplicar a tela } \\
\text { selante, observando que a região que não possui cola deve ficar sobre } \\
\text { a trinca, permitindo sua movimentação; } \\
\text { 4. Posteriormente preencher a canaleta de } 2 \mathrm{~mm} \text { com mástique ou massa } \\
\text { acrílica. Lixar e pintar. }\end{array}$ \\
\hline $\begin{array}{l}\text { Manifestação } \\
3\end{array}$ & $\begin{array}{l}\text { Eflorescência } \\
\text { nas vigas }\end{array}$ & 24 & $6^{\circ}$ & $\begin{array}{l}\text { 1. Trocar as telhas quebradas; } \\
\text { 2. Realizar a impermeabilização da laje com uma membrana líquida de } \\
\text { silicone ou outro impermeabilizante compatível; } \\
\text { 3. Para remover eflorescências, escovar a superfície com escova de } \\
\text { cerdas de aço e proceder a limpeza com solução de não corrosiva; } \\
\text { 4. Em seguida limpar bem a superfície para remover todos os resíduos e } \\
\text { deixar secar; } \\
\text { 5. Fazer o lixamento, limpeza do pó, se preciso aplicar o revestimento de } \\
\text { proteção e então pintar. }\end{array}$ \\
\hline
\end{tabular}


Quadro 2 - Resultado da Priorização

(Continuação)

\begin{tabular}{|c|c|c|c|c|}
\hline $\begin{array}{c}\text { Manifestação } \\
4\end{array}$ & $\begin{array}{l}\text { Eflorescência } \\
\text { nas lajes }\end{array}$ & 24 & $7^{\circ}$ & $\begin{array}{l}\text { 1. Trocar as telhas quebradas; } \\
\text { 2. Realizar a impermeabilização da laje com uma membrana líquida de } \\
\text { silicone ou outro impermeabilizante compatível; } \\
\text { 3. Para remover eflorescências, escovar a superfície com escova de } \\
\text { cerdas de aço e proceder a limpeza com solução de não corrosiva; } \\
\text { 4. Em seguida limpar bem a superfície para remover todos os resíduos e } \\
\text { deixar secar; } \\
\text { 5. Fazer o lixamento, limpeza do pó, se preciso aplicar o revestimento de } \\
\text { proteção e então pintar. }\end{array}$ \\
\hline $\begin{array}{c}\text { Manifestação } \\
12\end{array}$ & $\begin{array}{c}\text { Desplacamento } \\
\text { das cerâmicas }\end{array}$ & 18 & $8^{\circ}$ & $\begin{array}{l}\text { 1. Deve-se remover o revestimento cerâmico comprometido, limpar bem } \\
\text { a superfície, removendo-se sujeiras, pulverulências; } \\
\text { 2. Verificar o estado do emboço onde será reassentada a cerâmica, } \\
\text { fazendo-se o teste do bate-choco. Se forem identificadas áreas com } \\
\text { som cavo, remover o emboço nesses locais, reexecutar o emboço, } \\
\text { onde necessário; } \\
\text { 3. A regularização do emboço deve ser feita com argamassa colante (a } \\
\text { mesma usada para assentamento da cerâmica). A espessura dessa } \\
\text { camada de regularização não deve exceder a } 10 \mathrm{~mm} \text {; } \\
\text { 4. Fazer o reassentamento das placas cerâmicas. }\end{array}$ \\
\hline $\begin{array}{c}\text { Manifestação } \\
7\end{array}$ & $\begin{array}{l}\text { Desagregação } \\
\text { da argamassa }\end{array}$ & 18 & $9^{\circ}$ & $\begin{array}{l}\text { 1. Remover a argamassa afetada; } \\
\text { 2. Renovação da camada de chapisco, emboço e reboco; } \\
\text { 3. Impermeabilização; } \\
\text { 4. } \\
\text { Pintura. }\end{array}$ \\
\hline $\begin{array}{c}\text { Manifestação } \\
11\end{array}$ & Brecha vertical & 18 & $10^{\circ}$ & $\begin{array}{l}\text { 1. } \text { Retirada das raízes de árvores; } \\
\text { 2. Reforço da fundação; } \\
\text { 3. } \quad \text { Quebrar em Z, colocar barras de aço e completar com concreto. }\end{array}$ \\
\hline $\begin{array}{c}\text { Manifestação } \\
13\end{array}$ & $\begin{array}{l}\text { Fissuras a } 45^{\circ} \\
\text { nas cerâmicas }\end{array}$ & 12 & $11^{\circ}$ & $\begin{array}{l}\text { 1. Deve-se remover o revestimento cerâmico comprometido, verificar se } \\
\text { existem fissuras no emboço, se existir, tratar as fissuras de forma } \\
\text { adequada e fazer o reassentamento das placas cerâmicas. }\end{array}$ \\
\hline $\begin{array}{c}\text { Manifestação } \\
18\end{array}$ & $\begin{array}{c}\text { Fissuras a } 45^{\circ} \\
\text { nas paredes }\end{array}$ & 12 & $12^{\circ}$ & $\begin{array}{l}\text { 1. Fazer uma fenda local na fissura com uma espátula, em uma faixa de } \\
3 \mathrm{~cm} \text { em seu entorno. A abertura pode ser feita também com uma } \\
\text { escova de aço; } \\
\text { 2. Depois disso, colocar a massa acrílica na fenda, lixar e pintar com } \\
\text { tinta acrílica; } \\
\text { 3. Não se deve utilizar massa ou tinta PVA pois estas são rígidas, } \\
\text { podendo causar o surgimento de novas fissuras nas extremidades do } \\
\text { reparo. }\end{array}$ \\
\hline $\begin{array}{c}\text { Manifestação } \\
14\end{array}$ & Trincas no piso & 12 & $13^{\circ}$ & 1. Regularização das trincas e fraturas com uma argamassa corretiva. \\
\hline $\begin{array}{c}\text { Manifestação } \\
15\end{array}$ & $\begin{array}{l}\text { Recalque do } \\
\text { piso }\end{array}$ & 8 & $14^{\circ}$ & $\begin{array}{l}\text { 1. Preenchimento com geopolímero, são feitas perfurações, com } \\
\text { diâmetro inferior a } 3 \mathrm{~cm} \text {, são executadas onde foram verificados os } \\
\text { vazios ou solo de baixa capacidade de suporte. As perfurações } \\
\text { executadas para introdução das diminutas tubulações de cobre } \\
\text { permitem direcionar a resina diretamente no solo a ser tratado; } \\
\text { 2. O levantamento da edificação indica que o Geopolímero preencheu } \\
\text { todos os espaços vazios e enrijeceu suficientemente o solo; } \\
\text { 3. O renivelamento de afundamentos é realizado sem interferências, nem } \\
\text { a interrupção das atividades. } \\
\text { 4. Após isso pode ser feita a regularização onde necessário com } \\
\text { argamassa corretiva. }\end{array}$ \\
\hline $\begin{array}{c}\text { Manifestação } \\
16\end{array}$ & $\begin{array}{l}\text { Recalque da } \\
\text { calçada }\end{array}$ & 8 & $15^{\circ}$ & $\begin{array}{l}\text { 1. Após a estabilização da fundação, regularizar com uma argamassa } \\
\text { corretiva ou preencher com geopolímero. }\end{array}$ \\
\hline
\end{tabular}


Quadro 2 - Resultado da Priorização

(Continuação)

\begin{tabular}{|c|c|c|c|c|}
\hline $\begin{array}{c}\text { Manifestação } \\
2\end{array}$ & $\begin{array}{l}\text { Bolor/Mofo } \\
\text { nas vigas }\end{array}$ & 8 & $16^{\circ}$ & $\begin{array}{l}\text { 1. Para remover bolor e fungos, pode-se escovar a superfície com escova } \\
\text { de cerdas duras com solução de fosfato trissódico ( } 30 \mathrm{~g} \mathrm{de} \mathrm{Na}_{3} \mathrm{PO}_{4} \mathrm{em} \\
1 \text { litro de água) ou com solução de hipoclorito de sódio ( } 4 \% \text { a } 6 \% \text { de } \\
\text { cloro ativo); } \\
\text { 2. Em seguida limpar bem a superfície para remover todos os resíduos de } \\
\text { cloro e deixar secar, fazer o lixamento, limpeza do pó e reaplicar a } \\
\text { pintura de acabamento, utilizar tinta látex acrílica anti-mofo. }\end{array}$ \\
\hline $\begin{array}{c}\text { Manifestação } \\
10\end{array}$ & $\begin{array}{l}\text { Fissuração na } \\
\text { junta estrutural }\end{array}$ & 4 & $17^{\circ}$ & $\begin{array}{l}\text { 1. Como ela não está tendo sua real função, deve-se no mínimo aplicar } \\
\text { um selante na junta que está aberta e possibilita a infiltração de água } \\
\text { pela mesma, atingindo o emboço e causando prejuízos na aderência } \\
\text { das placas cerâmicas. }\end{array}$ \\
\hline $\begin{array}{c}\text { Manifestação } \\
1\end{array}$ & $\begin{array}{l}\text { Bolor/Mofo } \\
\text { nas paredes }\end{array}$ & 4 & $18^{\circ}$ & $\begin{array}{l}\text { 1. Para remover bolor e fungos, pode-se escovar a superfície com escova } \\
\text { de cerdas duras com solução de fosfato trissódico ( } 30 \mathrm{~g} \text { de } \mathrm{Na}_{3} \mathrm{PO}_{4} \text { em } \\
1 \text { litro de água) ou com solução de hipoclorito de sódio ( } 4 \% \text { a } 6 \% \text { de } \\
\text { cloro ativo); } \\
\text { 2. Em seguida limpar bem a superfície para remover todos os resíduos de } \\
\text { cloro e deixar secar; } \\
\text { 3. Fazer o lixamento, limpeza do pó e reaplicar a pintura de acabamento; } \\
\text { 4. Utilizar tinta látex acrílica anti-mofo. }\end{array}$ \\
\hline $\begin{array}{c}\text { Manifestação } \\
6\end{array}$ & $\begin{array}{c}\text { Descascamento } \\
\text { da pintura }\end{array}$ & 4 & $19^{\circ}$ & $\begin{array}{l}\text { 1. É sugerida nesta circunstância, que seja raspada e escovada a } \\
\text { superfície até que remova todas as partes defeituosas e prováveis de } \\
\text { apresentarem a mesma patologia, tomando-se assim ao mesmo tempo, } \\
\text { medidas corretivas e preventivas, evitando futuros custos; } \\
\text { 2. Em seguida, é necessário aplicar uma demão preparadora para que } \\
\text { seja aplicada a tinta de acabamento, e a vida útil da mesma seja } \\
\text { restabelecida; } \\
\text { A umidade superficial pode reduzir a aderência de muitas pinturas e, } \\
\text { portanto, é conveniente que, as superfícies estejam secas. }\end{array}$ \\
\hline $\begin{array}{c}\text { Manifestação } \\
9\end{array}$ & $\begin{array}{l}\text { Fissura } \\
\text { Horizontal }\end{array}$ & 4 & $20^{\circ}$ & $\begin{array}{l}\text { 1. Retificar a fissura ao máximo através da utilização de um disco de } \\
\text { desgaste; } \\
\text { 2. Aplicar um selante acrílico flexível. }\end{array}$ \\
\hline $\begin{array}{l}\text { Manifestação } \\
5\end{array}$ & $\begin{array}{l}\text { Infiltração nas } \\
\text { paredes }\end{array}$ & 4 & $21^{\circ}$ & $\begin{array}{l}\text { 1. Como a infiltração das paredes vem da laje, então deve-se trocar as } \\
\text { telhas quebradas; } \\
\text { 2. Impermeabilizar a laje; } \\
\text { 3. Deixar secar, limpar bem a superfície para remover todos os resíduos } \\
\text { e, então pintar. }\end{array}$ \\
\hline
\end{tabular}

Fonte: Autoria Própria (2019).

\section{CONSIDERAÇÕES FINAIS}

A maioria das manifestações patológicas identificadas na central de aulas IV da UFERSA, campus Mossoró, são relacionadas a umidade e recalque diferencial, repetindo-se por todo o prédio. $O$ fato de a edificação não possuir impermeabilização na laje e ter muitas telhas quebradas, caimento inadequado, resulta em vários problemas patológicos decorrente de umidade como foi apresentado no estudo. Os ensaios realizados e seus respectivos resultados foram de extrema importância no diagnóstico das manifestações patológicas, principalmente no que diz respeito às fissuras, trincas e, rachaduras a $45^{\circ}$.

Pelo fato de as fundações não ficarem expostas e consequentemente não serem acessíveis a revisões periódicas, os defeitos patológicos não costumam ser detectados com facilidade, então o resultado dos ensaios serviram para interpretar o comportamento do solo utilizado para o aterro da fundação. Tratando-se de um solo classificado como areia argilo-siltosa, as raízes e a água que é lançada proveniente dos aparelhos de ar-condicionado na fundação podem ter causado o seu adensamento, as raízes ainda podem influenciar de forma física na integridade dos pilares e fundações, assim causando o aparecimento das fissuras, desaprumos e piso afundado. Chegando à consideração que as raízes de árvores que estão próximas as fundações podem ter contribuído para o recalque diferencial do prédio. Em relação a utilização do Método GUT para o estabelecimento da ordem de prioridade de resolução entre os problemas encontrados, foi comprovado a sua aplicabilidade individual na área de estudo, visto que se tornou possível realizar a hierarquização de riscos referentes às manifestações patológicas avaliadas. 
Apesar de alguns graus de priorização terem abrangido mais de uma manifestação patológica, coube aos autores notar se as semelhanças em seus diagnósticos, causas e, até mesmo, no nível de deterioração dos elementos, e assim decidir qual manifestação teria a prioridade.

Recomenda-se a formação de uma equipe técnica para reparar, garantir e prolongar o desempenho, funcionalidade e vida útil do prédio, podendo ser embasada na metodologia aplicada neste trabalho. Bem como a realização de programas de manutenção eficazes para os edifícios que compõem a infraestrutura da Universidade.

Esse estudo corrobora também com a visão da pesquisa de Iantas (2010), consolidando a necessidade de intervenção das manifestações patológicas encontradas, visto que elas podem ser agravadas pela manutenção inadequada da edificação.

\section{REFERÊNCIAS}

ASSOCIAÇÃO BRASILEIRA DE NORMAS TÉCNICAS. NBR 6118: Projeto de estruturas de Concreto. Emd 1. Rio de Janeiro, 2007. 221 p.

ASSOCIAÇÃO BRASILEIRA DE NORMAS TÉCNICAS. NBR 6484: Solo - Sondagens de simples reconhecimentos com SPT - Método de ensaio. 2 ed. Rio de Janeiro, 2001. 17 p.

CORREA, Sonia Maria Barros. Probabilidade e Estatística. 2003. $2^{\circ}$ Ed. 116 p. Pontifícia Universidade Católica de Minas Gerais Belo Horizonte, 2003.

FERREIRA, Ivanilda Agustinho et al (Ed.). UTILIZAÇÃO DE FERRAMENTAS GERENCIAS NA AVALIAÇÃO DE MEDIDAS DE CONTROLES DE RISCOS NO TRABALHO: ESTUDO DE CASO EM CANTEIRO DE OBRAS NA CIDADE DE JOÃO PESSOA/PB. In: CAVALCANTI, Adriana Costa et al. TÓPICOS EM ADMINISTRAÇÃO. Belo Horizonte: Poisson, 2018. p. 1-247. Disponível em: https://poisson.com.br/2018/produto/topicos-emadministracao-volume-8/. Acesso em: 05 jan. 2019.

GOMES, L. Reavaliação e melhoria dos processos de beneficiamento de não tecidos com base em reclamações de clientes. Revista FAE. [S.I] 2006. Disponível em: https://revistafae.fae.edu/revistafae/article/view/427/323. Acessado em: 09 fev. 2019.

HELENE, P. R. L. Introdução da vida útil no projeto das estruturas de concreto. WORKSHOP SOBRE DURABILIDADE DAS CONSTRUÇÕES. São José dos Campos, 2001.

\section{MEDEIROS, Arthur. APLICAÇÃO DO ULTRA-SOM NA ESTIMATIVA DA PROFUNDIDADE DE FENDAS} SUPERFICIAIS E NA AVALIAÇÃO DA EFICÁCIA DE INJEÇÕES EM ELEMENTOS DE CONCRETO

ARMADO. Dissertação (Mestrado de Engenharia) - Universidade Federal de Santa Catarina, Florianópolis/SC, 2007, 180p.

NAZÁRIO, D; ZANCAN; E. Manifestações das patologias construtivas nas edificações públicas da rede municipal de Criciúma: Inspeção dos sete postos de saúde. Santa Catarina, 2011. Disponível em:

http://docplayer.com.br/279728 55-Manifestacoes-das-patologias-construtivas-nas-edificacoes-publicas-da-redemunicipal-de-criciuma-inspecao-dos-sete-postos-de-saude.html. Acesso em: 20 fev. 2019.

OLIVEIRA, Gabriel Ferreira de. Principais manifestações patológicas nas estruturas de concreto. Revista Especialize On Line, Brasília, v. 1, n. 12, p.1-21, dez. 2016. Anual. Disponível em: https://www.ipog.edu.br/revista-especializeonline/edicao-n12-2016/. Acesso em: 10 fev. 2019.

PERIARD, G. Matriz GUT: Guia Completo. 2011. Disponível em: http://www.sobreadministracao.com/matriz-gutguia-completo/. Acesso em: 03 fev. 2019.

TUTIKIAN, B; PACHECO; M. Boletín Técnico - Inspección, Diagnóstico y Prognóstico en la Construcción Civil. Merida, 2013. Disponível em: http://alconpat.org.br/wpcontent/ uploads/2012/09/B1_Inspe\%C3\%A7\%C3\%A3o-Diagn\%C3\%B3stico-e-

Progn\%C3\%B3stico-na-Constru\%C3\%A7\%C3\%A3o-Civil1.pdf. Acesso em: 05 fev. 2019 